\title{
AFORIZAÇÕES E FEMINISMO NA INTERNET: ESTUDO DE FRASES CURTAS EMPREGADAS NO MOVIMENTO PRIMAVERA DAS MULHERES
}

\author{
Cristina Rothier DUARTE ${ }^{1}$ \\ Lafayette Batista MELO ${ }^{2}$
}

\begin{abstract}
Resumo: Neste trabalho, tratamos da análise de frases curtas que tiveram destaque nas redes sociais e em notícias que circularam na internet, durante o último trimestre de 2015, ápice do movimento Primavera da Mulheres, com o objetivo de investigar o seu status de aforização, suas características enunciativas e o seu modo de funcionamento e de circulação. O corpus da pesquisa é composto pelas frases curtas "Meu amigo secreto" e "Chega de fiu fiu", selecionadas na internet por meio da ferramenta de busca do Google, bem como mediante trabalho interpretativo dos enunciados para a verificação de associação com o movimento feminista mencionado. Empregamos como aporte teórico os estudos de análise do discurso de linha francesa, sobretudo, publicações de Dominique Maingueneau. Observamos durante a pesquisa que, de forma associada às aforizações estudadas, surgiram outras aforizações que, apesar de não terem se panaforizado, circularam significativamente na mídia eletrônica perpetuando a memória discursiva do Movimento Primavera das Mulheres. Por outro lado, percebemos também que o uso dessas frases assumiu outros discursos que, embora, muitas vezes, remetam-se à defesa de minorias, não mais traziam o discurso de combate ao machismo.
\end{abstract}

Palavras-chave: Aforizações. Análise do discurso. Redes sociais. Primavera das mulheres.

\footnotetext{
${ }^{1}$ IFPB - Instituto Federal de Educação, Ciência e Tecnologia da Paraíba - Departamento de Letras. João Pessoa - Paraíba - Brasil. 58015-435 - cristinarothier@hotmail.com

2 IFPB - Instituto Federal de Educação, Ciência e Tecnologia da Paraíba - Unidade Acadêmica de Informática. João Pessoa - Paraíba - Brasil. 58015-435 - lafagoo@gmail.com
} 


\section{Introdução}

O movimento Primavera das Mulheres, considerado por Grillo, Oliveira e Buscato (2015) o movimento político mais importante do Brasil na atualidade, surgiu com o objetivo de combater uma cultura machista que, "muitas vezes, vê as vítimas como culpadas pelas agressões sofridas”. De acordo com as jornalistas, o estopim, ocorrido em outubro de 2015, foi uma série de mensagens de teor sexual, que circularam nas redes sociais, a respeito de Valentina, menina de 12 anos, participante do programa MasterChef Júnior.

Outro fato que corroborou para adesões ao movimento foi o projeto de Lei 5069/2013, de autoria do deputado do PMDB e presidente da Câmara dos Deputados, Eduardo Cunha, que, conforme a explicação da ementa de acréscimo do artigo 127-A, do Código Penal, "tipifica como crime contra a vida o anúncio de meio abortivo e prevê penas específicas para quem induz a gestante à prática de aborto”, além de acrescentar a “necessidade de exame de corpo de delito para atendimento pelo SUS (Sistema Único de Saúde) em casos de estupro” (ÁLVARES; CANCIAN, 2015).

Diante dessa conjuntura, mulheres - e homens também - , no intuito de manifestar sua indignação frente à relativa normalidade com que a sociedade trata o assédio masculino contra mulheres, à inversão dos papéis vítima/assediador e à inovação legislativa retrógrada, concomitantemente às passeatas do movimento, fizeram circular na internet algumas frases de protesto, por meio de sites de notícias, blogs feministas e redes sociais. Entre as frases criadas, adotaremos como corpus desta pesquisa: "Meu amigo secreto" e "Chega de fiu fiu” com o objetivo de investigar o seu modo de funcionamento e de circulação na mídia eletrônica. Contudo, inicialmente, trataremos da conceituação e das características das frases curtas, segundo uma perspectiva da análise do discurso de linha francesa, especialmente, dos estudos realizados por Dominique Maingueneau, para, então, partirmos para a análise do corpus. 


\section{Metodologia}

Adotamos nesta pesquisa a abordagem teórico-metodológica da análise do discurso de linha francesa, empregando especialmente os novos conceitos propostos por Dominique Maingueneau. O corpus da nossa pesquisa, conforme mencionado, é composto por frases curtas: "Meu amigo secreto" e "Chega de fiu fiu".

Para a construção do corpus, levamos em consideração que "os corpora em Análise do Discurso não são dados a priori. A questão de pesquisa é que determina a maneira mesmo como os corpora serão montados e frequentados” (BARONAS, 2013, p. 231). Assim, para sua constituição, utilizamos técnicas e estratégias de busca no Google não empregadas normalmente, com adequações especiais para esta pesquisa: a partir da inserção, na barra de pesquisa do Google, do termo de interesse entre aspas ("Chega de fiu fiu" e "Meu amigo secreto"), seguido de site: (a palavra site acompanhada de dois pontos) e do endereço da página desejada, no caso, a página do Twitter (por exemplo: “Chega de fiu fiu” site: https://www.twitter.com), obtivemos como resultado postagens feitas por usuários do Twitter, nas quais houve o emprego das frases curtas mencionadas. A partir dos resultados das buscas, realizamos uma análise interpretativa, a fim de verificar a adequação do conteúdo dessas publicações ao movimento Primavera das mulheres, selecionando, assim o nosso corpus.

Para efeito de verificação da ocorrência de buscas das frases “Chega de fiu fiu” e "Meu amigo secreto”, realizadas por usuários da internet, no último trimestre de 2015, período do ápice do movimento Primavera das Mulheres, utilizamos o Google Trends.

Ao se empregar essa ferramenta, o resultado que se obtém é um gráfico mostrando a frequência que o termo inserido na barra de busca foi procurado em determinado lapso temporal na internet.

Ao inserir o termo de interesse, no caso, as frases citadas, observamos que “Chega de fiu fiu” ${ }^{3}$ apareceu, com frequência, no período de 6 a 12 de dezembro de 2015; e "Meu amigo secreto"4, nos dias 27 e 28 de novembro do mesmo ano, totalizando,

\footnotetext{
3 Gráfico de ocorrências da frase curta "Chega de fiu fiu” no Google Trends:

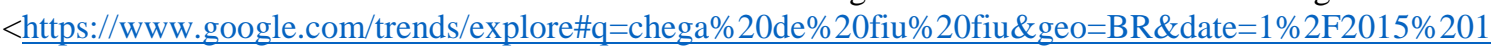
2m\&cmpt=q\&tz=Etc\%2FGMT\%2B3>. Acesso em: 13 mai. 2016.

4 Gráfico de ocorrências da frase curta "Meu amigo secreto" no Google Trends: $<\underline{\text { https://www.google.com/trends/explore\#q=meu\%20amigo\%20secreto\&geo=BR\&date=1\%2F2015\%2012 }}$ $\underline{m \& c m p t=q \& t z=E t c \% 2 F G M T \% 2 B 3>. ~ A c e s s o ~ e m: ~} 13$ mai. 2016.
} 
nesses intervalos, 100 (cem) ocorrências. O que significa que, nesse período, as frases pesquisadas foram usadas como termo de busca, por usuários da internet, 100 (cem) vezes.

\section{Aforização: conceitos em análise do discurso de linha francesa}

O uso social de frases curtas não é recente. Provérbios, máximas, slogans, frases de protesto, entre outros, sempre foram muito utilizados. No entanto, em razão da mídia eletrônica, a circulação, bem como o emprego de frases fora do seu contexto original ocorrem bem mais e com maior rapidez na internet, popularizando-se, ou, conforme modernamente dizemos, viralizando essas frases sem texto de um dia para o outro.

Foi o que ocorreu com as frases que compõem o corpus deste trabalho. Quase que imediatamente após seu surgimento, as frases "Meu amigo secreto", "Chega de fiu fiu” e outras como "Meu primeiro assédio", "Fora Cunha” provocaram adesões, como compartilhamentos, curtidas e comentários positivos, apenas citando o Facebook e o Twitter. Nessa conjuntura, convém, então, perquirir o que são destacabilidade, aforizações, entre outros conceitos pertinentes à análise do discurso de linha francesa.

De acordo com Maingueneau, aforização constitui enunciações que são, em razão da sua natureza, destacadas, ou seja, não são retiradas de um texto, mas já são naturalmente destacadas, como os slogans, os adágios etc. Aforização pode ser também destacada de um texto, e nesse caso,

[...] esta destacabilidade, que abre a possibilidade de uma destextualização, de uma saída do texto, entra em tensão com a dinâmica da textualização e vai na direção oposta à de integrar os constituintes do texto em uma operação que chamaremos de sobreasseveração (MAINGUENEAU, 2014, p. 15).

Assim, “a sobreasseveração põe em evidência uma sequência sobre um fundo textual, enquanto a aforização - ou mais precisamente, a enunciação aforizante - confere um estatuto pragmático específico a um enunciado desprovido de contexto" (MAINGUENEAU, 2012, p. 2).

No que diz respeito à sobreasseveração, Maingueneau (2012) ainda explica que o destacamento se dá em relação ao entorno textual, por meio de marcadores aspectuais, 
tipográficos, prosódicos, sintáticos, semânticos, lexicais etc. Por exemplo: o título de uma matéria jornalística retirado de algum trecho do texto, a chamada na capa de uma revista e o realçamento de uma frase em alguma ilustração do texto são sobreasseverações.

A destacabilidade, por sua vez, de acordo com Possenti (apud MAINGUENEAU, 2014), é um conjunto de propriedades que algumas frases possuem, fazendo-as salientes e possibilitando, eventualmente, sua circulação fora do texto-origem. "Sem texto, outro conceito trazido por Possenti, qualifica o final de um processo, que vai da destacabilidade ao destacamento, passando eventualmente por modificações que tornam a sequência mais pregnante” (POSSENTI apud MAINGUENEAU, 2014, p. 7, grifo do autor).

Esse destacamento poderá ser forte ou fraco. Será forte, quando a enunciação destacada puder circular independentemente do texto do qual foi retirada, e será, por outro lado, fraca, na hipótese da inexistência dessa autonomia, necessitando, assim, do texto-origem.

Em outras palavras, “a frase que é destacada de um texto pode muito bem permanecer em sua vizinhança. Assim, deve-se distinguir entre um destacamento forte, que implica uma separação do texto-fonte, e um destacamento fraco, caso em que a frase destacada fica contígua ao texto-fonte”, e complementa, "na imprensa escrita, como nos sites da web, as sobreasseverações são candidatas naturais ao destacamento fraco, na forma de manchetes, de intertítulos, ou de legendas de fotos” (MAINGUENEAU, 2014, p. 18-19).

Vejamos o seguinte exemplo de enunciação destacada de um texto:

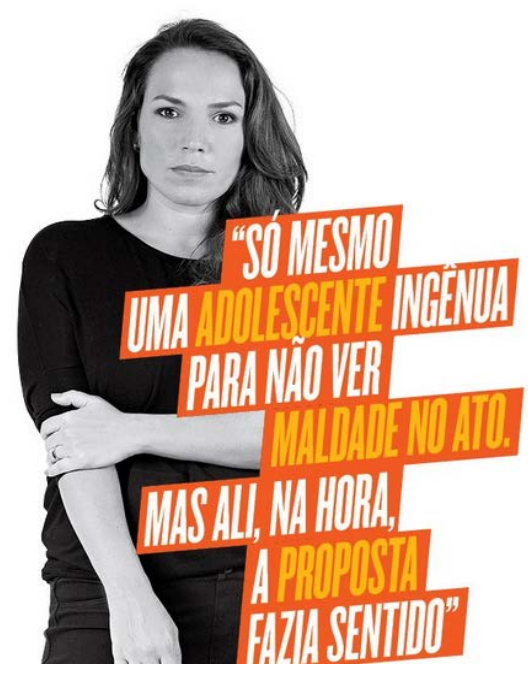

Figura 1: Enunciação aforizante destacada do texto

Fonte: <http://epoca.globo.com/vida/noticia/2015/11/meu-primeiro-assedio.html> 
A frase curta (Figura 1), "Só mesmo uma adolescente ingênua para não ver maldade no ato. Mas ali, na hora, a proposta fazia sentido”, retirada do texto original, Meu primeiro assédio, somente pode ser integralmente compreendida dentro do contexto trazido pelo texto:

[...] No ano seguinte, entretanto, uma viagem com a escola para as cavernas do Petar, um parque ecológico do Estado de São Paulo, mostrou exatamente o contrário. No segundo dia da excursão, o professor de biologia me chamou (e ao meu grupo de amigos mais próximos) para dizer que iria propor um exercício inovador que "só adolescentes maduros" como a gente conseguiriam entender. De lanterna em punho, saímos todos bem cedo para conhecer as cavernas. As duas classes que estavam no passeio se dividiram em grupos guiados por monitores da escola. O nosso, "maduríssimo", teve o "privilégio" de ser conduzido pelo tal professor. "Agora que estamos nesta parte profunda da caverna, onde não se ouve qualquer barulho além da nossa respiração, gostaria que vocês deixassem a lanterna sobre a pedra e sentassem aqui em volta”, disse ele, enquanto obedecíamos, iluminados somente pela luz do carbureto de seu capacete. "O que vou propor a vocês, Reich [William Reich, psicanalista austríaco morto em 1957] propôs nos anos 20 e 30 e foi mal interpretado por um bando de caretas. Vamos tirar as couraças da sociedade, tocando uns aos outros, no escuro e em silêncio", disse. Hoje, escrevendo essa frase, acho que só mesmo uma adolescente ingênua para não ver maldade no ato. Mas ali, na hora, a proposta fazia sentido. Estávamos no escuro de uma caverna, éramos "muito mais maduros que o resto da turma" e íamos desenvolver o tato, o sentido que os "caretas" não se permitem desenvolver ${ }^{5}$ (grifo nosso).

Como se vê, o enunciado destacado está sobreasseverado pela retomada que a autora adota (hoje, escrevendo essa frase), no entanto, esse destacamento é, de acordo com o que Maingueneau expõe, considerado fraco, já que “a frase destacada fica contígua ao texto" (MAINGUENEAU, 2014, p. 18).

Em outras palavras, a enunciação aforizante destacada do texto (MAINGUENEAU, 2012), também denominada secundária (MAINGUENEAU, 2015), que apresentamos na Figura 1, gerada a partir da sobreasseveração, ou seja, da "modulação da enunciação que formata um fragmento de texto como destacável, como candidato a uma destextualização" (MAINGUENEAU, 2011, p. 15, grifo do autor), é destituída de autonomia, tendo em vista que não circula fora do texto.

5 Depoimento de Marina Caruso, autora do artigo publicado na Revista Época versão digital, em 13/11/2015. Disponível em: <http://epoca.globo.com/vida/noticia/2015/11/meu-primeiro-assedio.html>. Acesso em: 25 jan. 2016. 
Assim, tendo em vista que somente pode ser compreendida se conhecermos o contexto em que está inserida, a frase em estudo não tem autonomia suficiente para podermos classificá-la como enunciação de destacamento forte. Nesse sentido, Maingueneau (2014) expõe que há o destacamento forte, geralmente, quando o textofonte não é acessível ao leitor ou ouvinte.

Como se vê, a aforização originada de um destacamento forte circula fora do texto de forma independente e representa uma verdade incontestável produzida por uma autoridade transcendente para um auditório universal, que, segundo Maingueneau (2011, p. 18), não se reduz a um destinatário localmente especificado: “a aforização institui uma cena de fala em que não há interação entre dois protagonistas situados sobre o mesmo plano”.

Depreende-se, então, que aforização pode ser uma enunciação dotada de autonomia em que o enunciador fala não para um destinatário X situado no mesmo plano que ele, mas para um número indeterminado de coenunciadores, de um plano em que se situa acima desses. Brunelli (2011) ensina que a aforização opõe-se à enunciação textualizante, pelo fato de aquela ter “um status pragmático especial”, qual seja: a fala de um enunciador considerado sujeito de direito, autoridade naquilo que enuncia.

Maingueneau (2011, p. 18), a propósito do enunciador, assevera que

[...] o locutor não é apreendido por tais ou tais facetas, mas em sua plenitude imaginária. É o sujeito em pessoa que se exprime. O aforizador - isto é, o enunciador de uma aforização - assume o ethos do locutor que ganha uma dimensão outra, que cresce no contato com uma fonte transcendental. Ele deve supostamente enunciar sua verdade, que não participa de nenhuma negociação.

Importante observar que o papel exercido pelo enunciador nas aforizações, tanto por natureza, quanto por destacamento, é comum, no entanto, a atividade interpretativa do coenunciador é requerida de forma diferenciada a depender do tipo de aforização (por natureza ou destacada de um texto). A respeito disso, Maingueneau (2011) explica que, no primeiro caso - a aforização por natureza, o coenunciador deve identificar a situação correspondente ao enunciado, ilustrando com o seguinte exemplo: “[...] o provérbio Pai avarento, filho pródigo poderá se aplicar desde que o destinatário possa opor o comportamento de um pai ao de um filho, ou de qualquer relação equivalente [...]”, de 
maneira que há uma homogeneidade na atividade interpretativa do coenunciador, pois o enunciado aforizante se encaixa ou não àquele contexto.

Já na aforização destacada de um texto, “a mesma aforização será tratada diferentemente conforme o enquadramento ao qual a submetemos” (MAINGUENEAU, 2011, p. 20), e a orientação do coenunciador se dá fortemente em razão da identidade do enunciador. Assim, enquanto uma aforização emitida por um filósofo levará o coenunciador a uma reflexão (enquadramento testemunhal), a aforização enunciada por um jornalista terá um caráter informativo (enquadramento informativo).

Observados os conceitos de frases curtas, sobreasseveração, aforização e o papel do coenunciador na atividade interpretativa das aforizações e da identidade do enunciador para o enquadramento da aforização, seguimos com o estudo do corpus desta pesquisa.

\section{Análise de frases curtas empregadas no movimento Primavera das Mulheres}

O corpus desta pesquisa - "Meu amigo secreto”, “Chega de fiu fiu” -, seguidas ou não de hashtag, conforme já mencionado, são destacadas de relatos de situações machistas e abusivas sofridas por mulheres, apresentando um enquadramento testemunhal, cujas características passaremos a estudar.

Melo (2015) considerou que, embora as frases sejam difundidas por sujeitos com perfis em redes sociais ou nas ruas, elas adquirem um aspecto autônomo, sem relações necessariamente diretas com textos anteriores ou posteriores. É o que ocorre no caso das frases em estudo. Embora sejam destacadas de relatos de situações machistas e abusivas sofridas por mulheres, apresentando inicialmente um enquadramento testemunhal, posteriormente, há uma despersonalização do enunciador, passando a circular como palavras de ordem enunciadas por um sujeito situado no alto e direcionadas a um auditório universal.

\section{Características enunciativas}

De acordo com nossos estudos, as frases pesquisadas possuem status de aforização, oriundas de um destacamento forte, tendo em vista que se tornaram autônomas, sendo, inclusive, passíveis de leituras diversas que a dos textos originais, 
além de que elas alimentam e têm o potencial de alimentar o que Maingueneau (2011) chama de regime de atualidade e regime memorial, ou seja, elas constituem conteúdo suficiente para nutrir as conversas rotineiras e têm a capacidade de serem sustentadas por uma memória discursiva a longo prazo.

O uso da aforização “Chega de fiu fiu” constitui uma série de advertências, a fim de modificar o comportamento masculino no que diz respeito ao assédio contra mulheres em espaços públicos, bem como visa, em uma leitura mais profunda, conscientizar tanto os homens quanto as mulheres que cantadas são formas de violência.

A expressão “amigo secreto” tem uma memória discursiva que nos remete às confraternizações de final de ano. No entanto, em novembro de 2015, assume um significado histórico distinto, começando a circular no Twitter e no Facebook, sequenciando movimentos feministas anteriores (“Chega de fiu fiu” e "Meu primeiro assédio”). A frase, nesse novo contexto, aparece como denúncia velada de circunstâncias machistas até agressões físicas cometidas por pessoas de convívio do denunciante. Além desse modo de circulação em postagens nas redes sociais, a aforização também aparece como título de matéria jornalística em revista eletrônica.

Conforme vimos, anteriormente, Maingueneau classifica o enquadramento interpretativo em informativo e testemunhal. Naquele, à aforização é dado um fazer saber (2011, p. 21), cujo conteúdo o coenunciador poderá agregar ao seu conhecimento de mundo, enquanto neste, o coenunciador toma ciência da experiência vivida pelo enunciador ou sua visão de mundo.

As frases curtas empregadas no movimento Primavera das Mulheres, que compõem o corpus deste estudo, como já exposto, são do enquadramento testemunhal, tendo em vista que os enunciados tratam de denúncias de comportamentos machistas contra mulheres realizadas pelos enunciadores.

O enquadramento testemunhal pode apresentar modalidades distintas a depender da distância que o enunciado tem do enunciador. Nesse sentido, Maingueneau (2011) expõe que o enquadramento testemunhal "pode passar tanto por um apagamento enunciativo que podemos classificar como sentencioso, quanto por um superinvestimento subjetivo personalizante”, o que significa dizer que, na modalidade apagamento enunciativo, o enunciado assume um caráter de testemunho geral, ou seja, o aforizador retoma valores que devem unir a comunidade, e, na modalidade de superinvestimento 
subjetivo personalizante, a aforização “está centrada na expressão direta dos afetos do locutor e não na afirmação de normas coletivas” (MAINGUENEAU, 2011, p. 22).

No caso das frases em estudo, percebemos o predomínio da modalidade de apagamento enunciativo. Muito embora os relatos tragam testemunhos de experiências e emoções pessoais ou presenciadas pelo enunciador, temos, nas frases curtas estudadas, regras gerais que devem ser adotadas pela sociedade, uma vez que têm como objetivo o fim do assédio e da violência contra a mulher e o tratamento igualitário entre os sexos. Vejamos alguns exemplos:

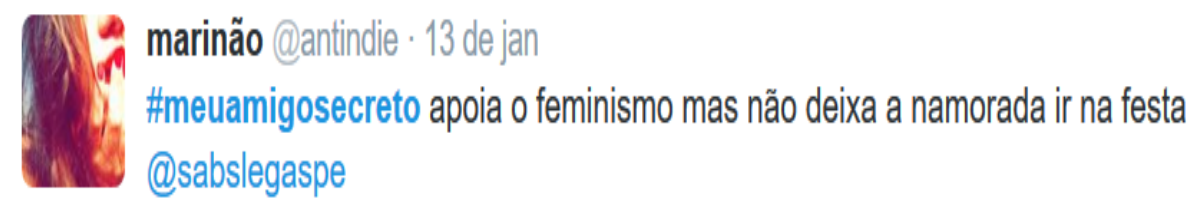

\section{Luisa Fein @lufuéin · 26 de jan \\ \#meuamigosecreto me deu um selinho forçado}

Figuras 2 e 3 - aforização \#meuamigosecreto

Fonte: $<\underline{\text { https://twitter.com/search?f=tweets\&vertical=news\&q=meuamigosecreto\&src=typd }>}$

Como podemos perceber, os relatos que acompanham a frase curta "Meu amigo secreto” tratam de denúncias particulares testemunhadas ou vividas pelo enunciador, no entanto, esse caráter pessoal não retira a força da norma geral que deve ser acolhida por todos.

$\mathrm{Na}$ aforização “Chega de fiu fiu”, observamos também o enquadramento interpretativo testemunhal na modalidade apagamento enunciativo, em que os enunciadores exprimem seu posicionamento político avesso ao tratamento machista conferido às mulheres em público por meio de assédio verbal (cantadas). 


\section{yang @the biaoliveira · 25 de dez de 2015}

Quantas são as grades que nos aprisionam? \#chegadefiufiu

\section{Renata Bittes @RenataBittes . 9 de jan \\ Eu só queria, como mulher, a liberdade de andar na rua sem buzinas, cantadas e olhares. \#chegadefiufiu \#machismonasruas}

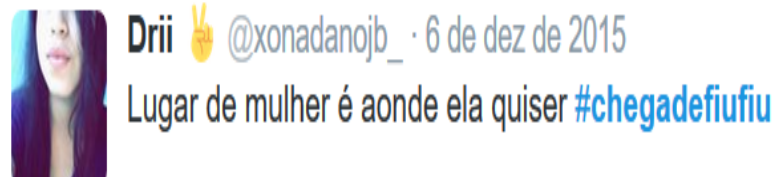

Figuras 4, 5 e 6 - aforização \#chegadefiufiu

Fonte: $<$ https://twitter.com/hashtag/chegadefiufiu $>$

O coenunciador das aforizações citadas consegue extrair do enunciado usado no movimento feminista um conteúdo que ultrapassa as denúncias relatadas que seguem as aforizações. Ao ler uma postagem ou cartaz com frases curtas como essas, o leitor constrói um enunciador único situado em um plano superior ao auditório em que ele, como coenunciador, está situado, e é levado a aderir ao discurso como uma verdade inegociável. Não importa qual seja a enunciação que siga às aforizações estudadas, sabese, em regra, que a voz trará um discurso político de protesto, na maioria das vezes, feminista.

\section{Modo de funcionamento e de circulação}

Como podemos observar, as frases curtas em estudo estão em formato de hashtag. Embora o estudo discursivo desse tipo de marcação (composto por uma ou mais palavraschave antecedidas da cerquilha) requeira uma pesquisa mais detalhada que não nos deteremos neste trabalho, é importante notar que ela ganha a função de criar uma relação particular entre os sujeitos e o acontecimento discursivo e melhora as possibilidades de criar grupos de pessoas em torno de um determinado tema ou assunto (DA SILVEIRA, 2013, p. 2). 
Foi justamente o que ocorreu com as frases do corpus deste trabalho. Devido à facilidade criada pela hashtag, essas frases circularam nas redes sociais intensamente, alcançando revistas eletrônicas, bem como a mídia impressa.

Durante a coleta de dados, verificamos também aforizações destacadas do texto não seguidas por hashtag relacionadas à “Chega de fiu fiu”, como a seguinte:

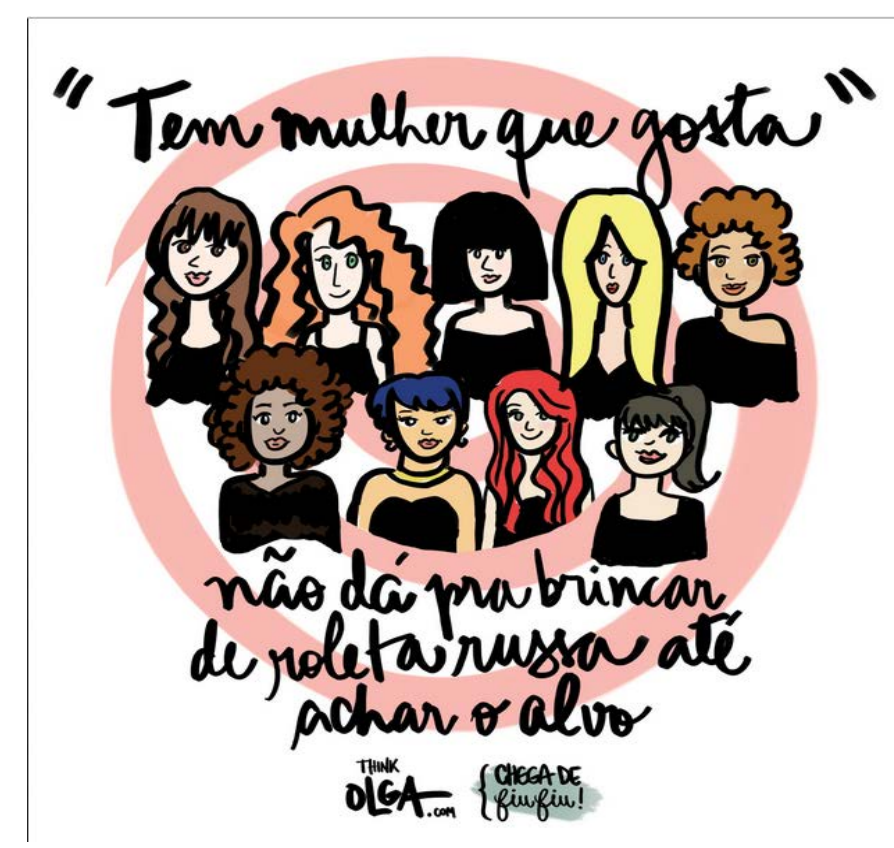

Figura 7 - Aforização sem hashtag destacada do texto

Fonte: <http://www.revistaforum.com.br/questaodegenero/wp-

\section{content/uploads/2014/11/fiufiu1.jpg>}

A frase curta "Não dá pra brincar de roleta russa até achar o alvo” foi retirada dos termos (em destaque na transcrição a seguir citada) de uma entrevista concedida por Juliana de Faria, jornalista e fundadora do blog Think Olga, responsável por uma campanha de combate ao assédio sexual em espaços públicos, à revista eletrônica Revista Fórum, em que diz:

Quando um cara assedia uma mulher na rua, ele fala que ela está sexualmente possível. E isso é extremamente recompensador para uma mulher que tem o sexo como validação do seu próprio ser. E TUDO BEM que essa mulher opte por ser assim. O problemático é existir uma sociedade que entenda todas as mulheres dessa forma e que crie homens que assediem (e amedrontem, humilhem, maltratem) desconhecidas sem seu consentimento como se fosse uma roleta russa (grifo nosso). 
Essa aforização foi constituída a partir de uma alteração do texto-origem, o que significa que não houve a intenção do locutor de promover a sobreasseveração, no entanto, o jornalista, ao realizar essa alteração, confere ao anunciado uma "mudança de estatuto pragmático”, ou seja “o enunciado destacado não é mais um fragmento do texto”, mas uma aforização (MAINGUENEAU, 2014, p. 27).

Realizando nova pesquisa na internet, empregando na ferramenta de busca do Google os termos "Não dá pra brincar de roleta russa até achar o alvo”, verificamos resultados cujos conteúdos são de discurso feminista contra o assédio, no entanto não com o caráter panafórico (BARONAS; COX, 2013; BARONAS, 2013) que as hashtags proporcionaram com \#chegadefiufiu e \#meuamigosecreto. Porém, a não panaforização não retira dessa frase o status de aforização.

Acerca da panaforização, Baronas (2013, p. 226) explica que esse fenômeno surge a partir de

[...] um certo número de aforizações [que] são tomadas em um processo de tipo pandêmico: durante um período curto é possível observar a circulação dessas aforizações em todas as mídias e às vezes com uma frequência muito elevada, com estatutos muito diversos: título de um artigo de jornal ou de uma página da internet, frase que circula na parte de baixo do monitor de um canal de informação televisiva, título de um vídeo sobre o Youtube, etc.

Além do fato de a não panaforização não retirar da frase "Não dá pra brincar de roleta russa até achar o alvo” o status de aforização, ao partir da comparação entre essa frase curta e o texto do qual ela foi extraída, também verificamos uma alteração, que, contudo, não apresenta divergência da entrevista. Ao contrário, a frase "Não dá pra brincar de roleta russa até achar o alvo” reforça o conteúdo do texto e facilita o processo de memorização, o que colabora para sua participação no regime de atualidade e no regime memorial. Muito embora não exista a divergência, a aforização diferencia-se do seu texto de origem devido ao papel assumido pelo enunciador, que "supostamente anuncia a sua verdade, subtraída da negociação” (MAINGUENEAU, 2012, p. 3). O que não se dá com um texto extenso.

Outra frase curta empregada no movimento feminista relacionada à frase "Chega de fiu fiu” foi “Caminhar por um espaço público não torna meu corpo público”. Essa frase curta não apresentou resultado significativo em buscas nas redes sociais, todavia, 
utilizando a ferramenta de busca do Google, encontramos vários resultados que nos remetem a sites que trazem a frase relacionada à campanha de combate ao assédio contra mulheres.

Durante as buscas, percebemos que a aforização “Chega de fiu fiu” assumiu também outros modos de circulação, tendo em vista que há frases que a acompanham não implicando o contexto originário de discurso feminista ou tratando-o em forma de humor:

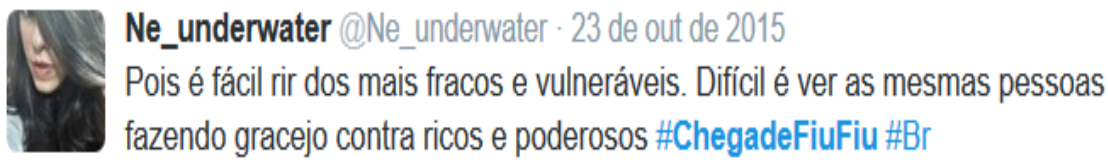

Figura 8 - Discurso a favor das minorias

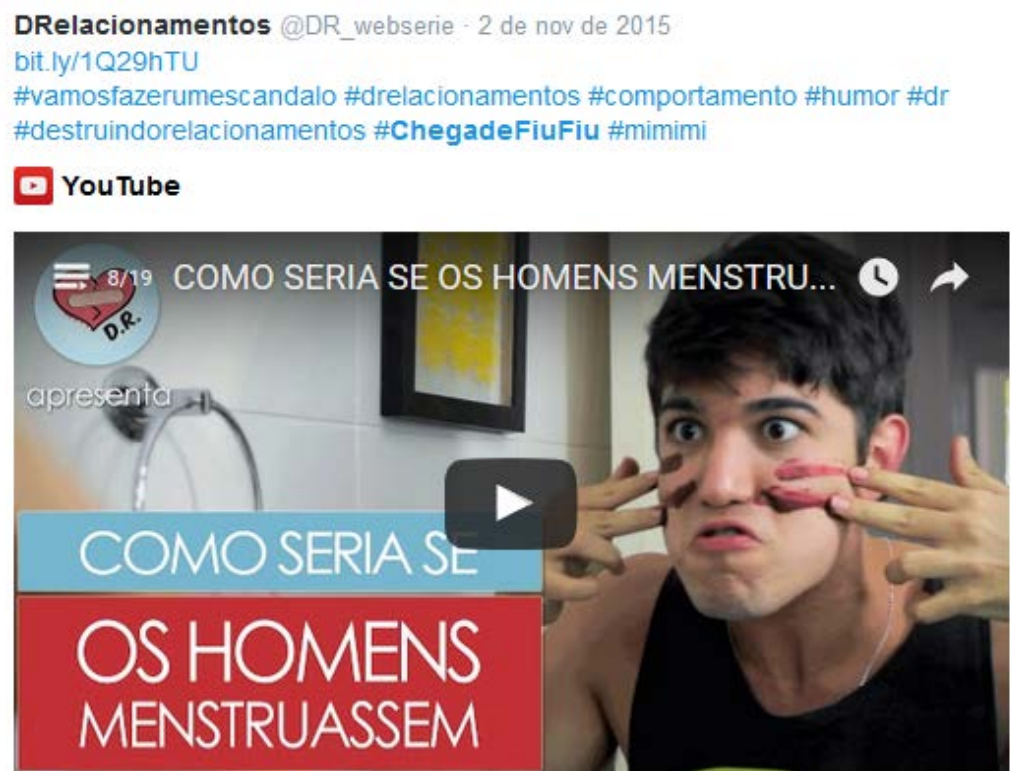

Figura 9 - Discurso feminista em tom de humor

Fonte: $<$ https://twitter.com/hashtag/chegadefiufiu $>$

Esse processo de transformação também ocorreu com a aforização “Meu amigo secreto”, que se deslocando do contexto histórico originário, hoje, apresenta, também, denúncias contra o racismo e a pedofilia, portanto fora do seu contexto original: 


\section{Rodrigo Scaliante @scaliant_ariza.5 de fev}

\#meuamigosecreto acha justo pagar uma mixaria p prof no contra-cheque de

fev pq em jan não tem aula.

Figura 10 - Discurso político-salarial

\section{Caroles Z.077@carolesZO·2 de fev}

\#MeuAmigoSecreto posta coisas sobre racismo pra ganhar likes no facebook

Figura 11 - Discurso sobre preconceito racial

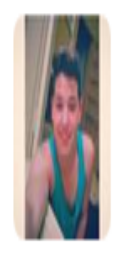

Allan Spier @ S Spiriento 1 de fev

\# MeuAmigoSecreto luta contra o machismo na sociedade e adora ser

chamada de Atvisista mas ela é contra o casamento gave e tudo que os envolve.

Figura 12 - Discurso homofóbico

Fonte: $<$ https://twitter.com/search?f=tweets\&vertical=news\&q=meuamigosecreto\&src=typd $>$

A partir dos exemplos acima, observamos que a aforização "Meu amigo secreto" continua com a função de denúncia velada, no entanto, o contexto histórico de manifestação contra o machismo sofre um apagamento e assume um novo formato.

\section{Considerações finais}

Embora a origem das aforizações seja milenar, a velocidade de circulação de frases curtas e seu potencial para adquirir a condição de enunciação aforizante assumiram proporções inimagináveis após o surgimento das redes sociais. Assim, contemporaneamente, uma frase destacada de um texto qualquer ou criada de forma autônoma pode, de um dia para o outro, circular intensamente nas redes, viralizar e avocar um caráter panafógico, a depender do contexto social que a cerca.

No caso das frases "Chega de fiu fiu” e "Meu amigo secreto”, verificamos que o contexto histórico em que estão inseridas reclamava frases curtas de protesto que apresentassem um discurso político de cunho feminista e remetessem os coenunciadores à 
memória discursiva que o movimento Primavera das Mulheres representa, a fim de conferir às manifestações o maior número de adesões possível, notadamente, nas redes sociais. E foi o que aconteceu, imediatamente após o surgimento das frases curtas que fazem parte do corpus da nossa pesquisa: elas se propagaram no Facebook e no Twitter, fazendo com que o movimento nascido no Sudeste criasse proporção nacional, fortalecendo-se, e, principalmente, disseminando a ideia de combate ao assédio e à violência contra as mulheres, conscientizando sobre o perigo de se banalizar as “cantadas” e de não denunciar agressões verbais e físicas.

Mediante os estudos realizados, pudemos verificar as características enunciativas e o modo de circulação das enunciações aforizantes "Chega de fiu fiu” e "Meu amigo secreto”. Originadas a partir de um movimento feminista que visa ao empoderamento feminino no combate a comportamentos machistas, essas frases ganharam força, devido à destacabilidade que lhes foi conferida, passando a circular como frases sem texto, ou seja, de forma autônoma, devido a suas caraterísticas enunciativas favorecedoras a essa circulação fora do texto-origem.

Observamos durante a pesquisa que, de forma associada às aforizações estudadas, surgiram outras aforizações que, apesar não terem se panaforizado, circularam significativamente na mídia eletrônica perpetuando a memória discursiva do Movimento Primavera das Mulheres. Por outro lado, percebemos também que o uso dessas frases assumiu outros discursos que, embora, muitas vezes, remetam à defesa de minorias, não mais traziam o discurso de combate ao machismo.

Verificamos também, sem muito aprofundamento, já que extrapolaria os objetivos a que nos propomos neste momento, que a hashtag tem um papel importante na circulação de frases curtas, de modo que seu estudo se revelou oportuno para uma futura pesquisa.

Além disso, seguindo o desenvolvimento histórico dos protestos de um modo geral, é possível notar que houve uma reelaboração dos gêneros cartaz e grito de ordem, passando as frases (orais ou escritas) de manifestações a aparecer, sem extinção daqueles, como publicações de redes sociais, análise que também merece uma investigação atenta. 
DUARTE, Cristina Rothier; MELO, Lafayette Batista. Aphorizations and feminism on the internet: a study of short sentences used in the movement Primavera das mulheres. Revista do Gel, v. 14, n. 1, p. 269-287, 2017.

\begin{abstract}
The focus of this paper is to analyze short sentences that were popular in social networks and news that circulated on the internet during the last quarter of 2015. This period was the peak of the movement Primavera da Mulheres. The analysis aimed to investigate the status of aphorization of these sentences, their characteristics of enunciation and their functioning and circulation mode. The corpus of the research is composed of two short sentences, which were "Meu amigo secreto" and "Chega de fiu fiu", selected on the internet through Google search engine and then carrying out an interpretative work of the sentences in order to find any relation with the feminist movement mentioned. The theoretical basis chosen for this work was the French discourse analysis - especially Dominique Maingueneau's works. During the research, it was observed that other aphorizations emerged associated with the studied aphorizations and, despite not having panaphorization, they significantly circulated in the electronic media perpetuating the discursive memory of Primavera da Mulheres movement. On the other hand, the use of these sentences incorporated other discourses that, despite defending minorities, no longer carried a discourse combating male chauvinism.
\end{abstract}

Keywords: Aphorizations. Discourse analysis. Social networks. Primavera da Mulheres.

Submetido em: 12/06/2016.

Aceito em: 31/08/2016.

\title{
Referências
}

ÁLVARES, D.; CANCIAN, N. Câmara aprova projeto que dificulta aborto legal e pune venda de abortivos. Folha de São Paulo, 2015. Disponível em:

$<$ http://www1.folha.uol.com.br/cotidiano/2015/10/1696664-camara-aprova-projeto-quedificulta-aborto-legal-e-pune-venda-de-abortivos.shtml> . Acesso em: 25 jan. 2016.

ARRAES, J. “Chega de fiu fiu”: um documentário sobre cantadas e assédio sexual. Revista Fórum, Seção Questão de Gênero. Disponível em:

$<$ http://www.revistaforum.com.br/questaodegenero/2014/11/21/chega-de-fiu-fiu-umdocumentario-sobre-cantadas-e-assedio-sexual/> . Acesso em: 21 nov. 2014.

BARONAS, R. L. Da panaforização à metaforização: o caso de uma pequena frase sem eira nem beira textual. Revista da ABRALIN, v. 12, n. 2, p. 219-248, 2013. Disponível em: <http://revistas.ufpr.br/abralin/article/view/38249/23344> . Acesso em: 19 jan. 2016. 
BARONAS, R. L.; COX, M. I. P. Por uma vida melhor na mídia: discurso, aforização e polêmica. Linguagem em (Dis)curso, v. 13, n. 1, p. 65-93, 2013. Disponível em: $<$ http://www.scielo.br/scielo.php?script=sci_arttext\&pid=S1518-76322013000100004>. Acesso em: 19 jan. 2016.

BRUNELLI, A. F. Aforização no discurso de autoajuda. Revista do GEL, v. 8, n. 1, p. 125-137, 2011. Disponível em: <https://revistadogel.gel.org.br/rg/article/view/51>. Acesso em: 19 jan. 2016.

CÂMARA DOS DEPUTADOS. Projeto de Lei 5069/2013. Disponível em: $<$ http://www2.camara.leg.br/proposicoesWeb/fichadetramitacao?idProposicao=565882 > . Acesso em: 25 jan. 2016.

CARUSO, M. Meu primeiro assédio. Revista Época. Seção Vida. Disponível em: $<$ http://epoca.globo.com/vida/noticia/2015/11/meu-primeiro-assedio.html>. Acesso em: 25 jan. 2016.

DA SILVEIRA, J. Análise discursiva da hashtag\# Onagagné: entre a estrutura e o acontecimento. VI Seminário de Estudos em Análise do Discurso, UFRGS, 2013. Disponível em: $<$ http://analisedodiscurso.ufrgs.br/anaisdosead/6SEAD/SIMPOSIOS/AnaliseDiscursivaD aHashtag.pdf >. Acesso em: 19 jan. 2016.

GRILLO, C.; OLIVEIRA, G.; BUSCATO, M. A primavera das Mulheres. Revista Época, Seção Vida, 2015. Disponível em: $<$ http://epoca.globo.com/vida/noticia/2015/11/primavera-das-mulheres.html>. Acesso em: 25 jan. 2016.

MAINGUENEAU, D. Aforização, enquadramento interpretativo e configuração humanista. Coleção Mestrado em Linguística, Franca, Unifran, v. 6, p. 15-34, 2011. Disponível em: $<$ http://publicacoes.unifran.br/index.php/colecaoMestradoEmLinguistica/article/view/542>. Acesso em: 19 jan. 2016.

Aforizações políticas, mídias e circulação de enunciados. Linguasagem Revista Eletrônica de Popularização Científica em Ciências da Linguagem, n. 20, p. 1-18, 2012. Disponível em:

$<$ http://www.letras.ufscar.br/linguasagem/edicao20/artigos/artigo_001.pdf $>$. Acesso em: 19 jan. 2016.

Frases sem texto. Tradução de Sírio Possenti et al. São Paulo: Parábola editorial, 2014.

Discurso e análise do discurso. Tradução de Sírio Possenti. São Paulo: Parábola editorial, 2015. 
MELO, L. B. Quando o gigante acorda, vai pra rua e sai do Facebook: frases em movimento. Cadernos de Estudos Linguísticos, v. 56, n. 2, 2015. Disponível em: $<$ http://revistas.iel.unicamp.br/index.php/cel/article/view/4475 $>$. Acesso em: 19 jan. 2016.

POSSENTI, S. Notas sobre gênero, uma questão teórica e metodológica. Revista da ABRALIN, v. 11, n. 2, 2012. Disponível em:

<http://revistas.ufpr.br/abralin/article/view/32530>. Acesso em: 19 jan. 2016. 